\title{
A Justification of Broach-Plow's Parameters of the Ridge-Stepped Ploughing
}

\author{
Bakhadir Mirzaev", Farmon Mamatov and Obid Tursunov* \\ Tashkent Institute of Irrigation and Agricultural Mechanization Engineers, 100000 Tashkent, \\ Uzbekistan
}

\begin{abstract}
While processing the soil with traditional plows at the same depth, a plow sole is formed in the subsurface layer, which leads to a deterioration in moisture absorption by the lower subsurface soil layer. As a result, water erosion occurs on the slopes. To overcome these limitations, the authors proposed an improved linear-step plow for soil slopes processing. Analytical expressions were obtained for determination the main parameters and traction resistance of the linearly-stepped broachplow. It was indicated that the turnover of the layers with the lowest energy costs is provided with the following parameters of the plow of odd hulls: plow length is $75 \mathrm{~cm}$, plow width is $25 \mathrm{~cm}$, stabilizing plate height is 15 $\mathrm{cm}$, and the minimum distance from the ploughshare toe to the stabilizing plate is $25 \mathrm{~cm}$. An installation angle of the plate to the furrow bottom, the length of the plate and the width of the wing holders, as well as the physical and mechanical properties of the soil have a significant impact on the traction resistance of the hedge.
\end{abstract}

\section{Introduction}

It is known $[1,2,3,4]$ that a plow sole is formed with annual ploughing by standard plows at the same depth in the subsoil, the density of which exceeds by 2 or more the density of the arable layer. On the slopes, a large difference in densities leads to a deterioration of the moisture absorption by the lower subsurface soil layer. As a result, the subsurface drainage and water erosion occurs on the slopes.

It is known that subsurface drainage can be adjusted using deep processing, step ploughing, grounding, chipping and etc. $[1,2,5,6]$.

One of the promising ways of the main tillage is smooth ploughing using a new technology, which involves a full turn $\left(180^{\circ}\right)$ of soil layers and laying them in their own furrows. $[7,8,9,10,11,12]$. This method is carried out with frontal and linear-step plows.

The linear-step plow consists of screw plow hulls displaced relative to each other. Each hulls is equipped with broach-plows (broach-plow is an additional hull, mounted behind the main hull of the front plow, which turns the soil layers for $180^{\circ}$ and rolls them in one direction) with working surfaces facing the reversible-dumping surfaces of the hulls $[7,8$,

\footnotetext{
Corresponding authors: bahadir.mirzaev@bk.ru, obidtursunov@gmail.com
} 
$9,10]$. When tilling the soil of the slopes with this plow, the bottom of the furrow and the surface of arable land are smooth. As a result, the soil's ability to retain and accumulate rainwater deteriorates, resulting in water erosion. In addition, the turnover of the layers on the slopes of $180^{\circ}$ within its own furrow requires high energy costs.

To address these limitations, the authors developed an improved linear-step plow for tillage soil slopes.

\section{Research Methods}

The basic principles and methods of classical mechanics, mathematical analysis and statistics were used in this study.

\section{Results and Discussion}

A broach-plow shifts the layer towards the main hull in the developed plow for ridgestepped ploughing [12]. As a result of the mutual impact on the soil hull and the additional shifting working hull (broach-plow), the layer is wrapped around its longitudinal axis. Therefore, the quality of the technological process of turning a layer by hull depends on the location of the broach-plow relative to the main hull, as well as its design parameters.

In the plow for ridge-stepped ploughing, a broach-plow is attached to the main plowshare of the hull with the help of a short plowshare (Fig. 1). A broach-plow consists of a stabilizing plate 2 with a bracket, a short ploughshare 3 and a wing 4 . A plowshare 3 of the broiler is welded to the stabilizing plate 2 . The wing is attached to the bracket stabilizing plate 2. Equations should be centred and should be numbered with the number on the right-hand side.
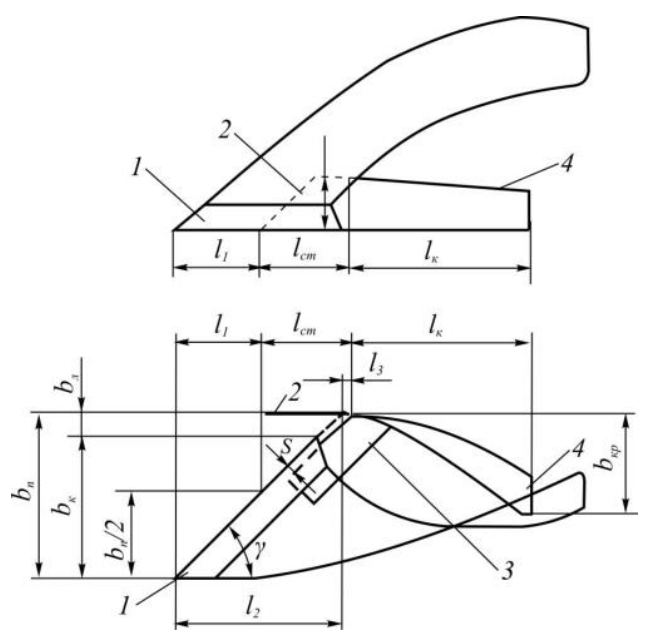

Fig. 1. Broach-plow and plow hull mutual arrangement

A stabilizing plate should act on the layer at the moment of the beginning the lifting of its center of gravity. This will happen when the center of gravity of the layer enters the plowshares of the hull. On this basis, the greatest distance from the toe of the plowshare to the stabilizing plate is calculated below $[9,13]$ :

$$
l_{1}=0,5 b_{n} \operatorname{ctg} \gamma
$$

The distance from the plowshare toe in the horizontal surface to the point A of intersection of the plowshare blade line with the longitudinal axis of the broach-plow's 
stand is calculated using the formula below $[9,13]$ :

$$
l_{2}=b_{n} c t g \gamma
$$

The distance from the point of intersection of the plowshare blade to the wing of the broach-plow is equal to [13]:

$$
l_{3}=\frac{s}{\sin \gamma},
$$

where $s$-displacement dimension of the broach-plow plowshare plowshare relative to the plowshare hull

The length of the stabilizing plate can be found from the condition that the wing of the broach-plow will start to act from the point of contact of the broach-plow's plowshare with a stabilizing plate:

$$
l_{c m}=l_{2}-l_{1}+l_{3} \text {. }
$$

Using the values $l_{1}, l_{2}$ and $l_{3}$ in (4.12), we obtain the formula below:

$$
l_{c m}=0,5 b_{n} c t g \gamma+\frac{s}{\sin \gamma} \text {. }
$$

As can be seen from (1), (2), (3) and (5) the rational location of the broach-plow relative to the main hull and the length of the stabilizing plate depends on the width of the soil layer $(b p)$ and the blade plowshare hull's angle of inclination to the furrow wall $(\gamma)$.

The height of the stabilizing plate $h$ should be sufficient to shift the layer without destroying it. This condition is achieved when the height of the action zone of the broachplow is greater than the height of the layer's center of gravity. Based on this[9]:

$$
h_{n \pi} \geq 0,5 a_{\max } .
$$

The maximum depth of the plow is $30 \mathrm{~cm}$. Then $h \geq 15 \mathrm{~cm}$.

The front cutting part of the stabilizing plate is set at an angle $\alpha \mathrm{c}$ to the horizon. The angle is selected from the condition of cutting soil with a slip, i.e. $\alpha_{\mathrm{c}}<(\pi / 2-\varphi)$.

Let's take into consideration the forces acting on the broach-plow.

As can be seen from Fig. 2, the total traction resistance $R_{3}$ of the broach-plow is defined as the sum of the horizontal component forces acting on the plowshare $R_{x}^{r}$, stabilizing plate $R_{x}^{n \pi}$ and broach-plow wing $R_{x}^{\kappa p}$.

$$
R_{3}=R_{x}^{\pi}+R_{x}^{n \pi}+R_{x}^{\kappa p}
$$



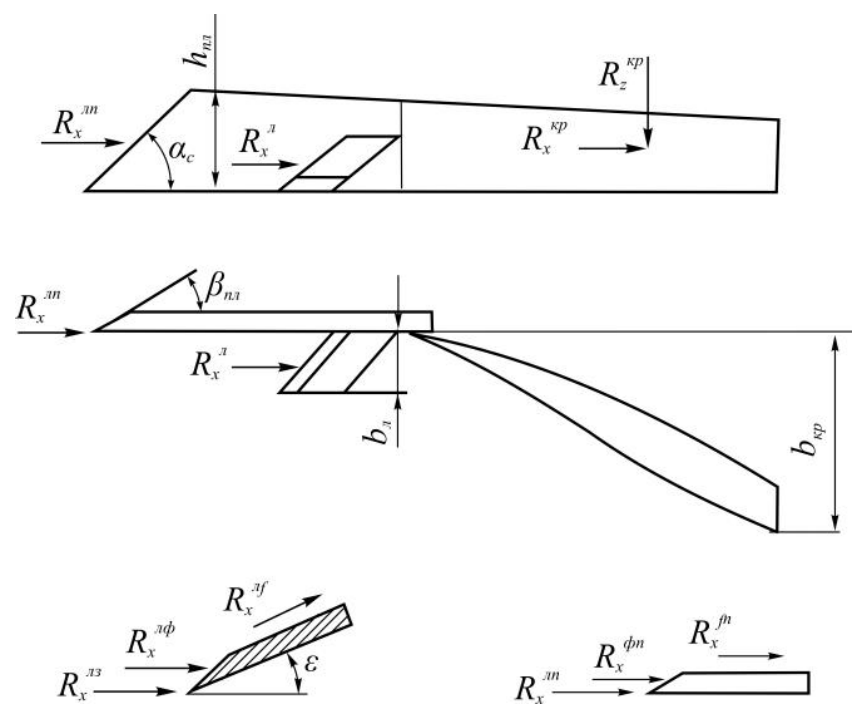

Fig. 2. Range of forces acting on the broach-plow

Traction resistance plowshare of the broach-plow consists of blade resistance $R_{x}^{л 3}$, facets $R_{x}^{\pi \phi}$ and surface friction force $R_{x}^{n f}$

$$
R_{x}^{\pi}=R_{x}^{\pi 3}+R_{x}^{\pi \phi}+R_{x}^{\pi f}
$$

Due to the slight tilt angle of the plowshare $\varepsilon$ to the bottom of the furrow, we neglect the tilt of the plowshare. Traction resistance of the blade, facet and friction forces on the plowshare's surface, respectively, are determined by the formula below [13]:

$$
\begin{gathered}
R_{x}^{л 3}=\sigma_{0} \delta b_{л}(1+f \cos \gamma), \\
R_{x}^{л \phi}=p \frac{t_{л}}{\sin \beta_{\pi}} b_{\pi}(1+f \cos \gamma), \\
R_{x}^{ת f}=f \rho^{1} b_{\pi}^{2} .
\end{gathered}
$$

Then,

$$
R_{x}^{\pi}=b_{л}(1+f \cos \gamma)\left(\sigma \delta+p \frac{t_{\pi}}{\sin \beta_{л}}\right)+f \rho^{1} b_{\pi}^{2},
$$


where $\sigma_{0}$ - temporary soil resistance to knife blade crushing; $\delta$ - blade thickness; $p$ soil pressure on the facet of the plowshare; $t_{n}$ - thickness plowshare of the broach-plow; $\beta_{n}-$ plowshare sharpening angle of the broach-plow; $p^{1}$ - specific pressure on the plowshare surface; $b_{n}$ - plowshare width of the broach-plow.

Stabilizing layers's traction resistance (Fig. 3) consists of the blade's resistance $R_{x}^{j n}$, facet $R_{x}^{\phi n}$ and friction forces on the surface of the layers $R_{x}^{f n}$

$$
R_{x}^{n \pi}=R_{x}^{\pi n}+R_{x}^{\phi n}+R_{x}^{f n}
$$

The components of the stabilizing plate's traction resistance are respectively determined by:

$$
\begin{array}{r}
R_{x}^{\pi n}=\sigma h_{n \pi} \delta\left(1+f \cos \alpha_{c}\right), \\
R_{x}^{\phi n}=p \frac{t_{n л}}{\sin \beta_{n л}} h_{n л}\left(1+f \cos \alpha_{c}\right), \\
R_{x}^{f n}=f \rho_{1}\left(l_{c m} h_{n л}-\frac{h_{n \pi}^{2}}{2} \operatorname{ctg} \alpha_{c}\right) .
\end{array}
$$

Then,

$$
R_{x}^{n n}=\left(p \frac{t_{n l}}{\sin \beta_{n л}}+\sigma \delta\right)\left(1+f \cos \alpha_{c}\right) h_{n л}+f \rho_{1}\left(l_{c m} h_{n n}-\frac{h_{n,}^{2}}{2} c \operatorname{tg} \alpha_{c}\right),
$$

where $\alpha_{\mathrm{c}}$ - angle of inclination of the blade plate to the bottom of the furrows in the longitudinal-vertical surface; $f$ - coefficient of soil friction on steel; $\beta_{\text {пл }}$ - leyer sharpening angle; $t_{n л}$ - layer thickness; $\rho_{1}$ - specific pressure during the collapse of the lateral face of the layer.

The traction resistance of the wing of the broach-plow is determined by the following formula [13]

$$
\boldsymbol{R}_{x}^{\kappa p}=k f_{1} h_{\kappa p} b_{\kappa p}
$$

where $k$ - specific soil resistivity, $f_{1}$ - internal friction coefficient; $h_{k p}-$ middle wing height; $b_{\kappa p}$ - width of the wing in horizontal.

Incorporating (12), (17) and (18) into (7), we get: 


$$
\begin{aligned}
R_{3}= & b_{л}(1+f \cos \gamma)\left(\sigma_{0} \delta+\frac{p t_{n}}{\sin \beta_{л}}\right)+f \rho^{1} b_{л}^{2}+\left(\frac{p t_{n л}}{\sin \beta_{n л}}+\sigma \delta\right) \times \\
& \times\left(1+f \cos \alpha_{c}\right) h_{n л}+f \rho_{1}\left(l_{c m} h_{n л}-\frac{h_{n l}^{2}}{2} \operatorname{ctg} \alpha_{c}\right)+k f_{1} h_{n p} b_{k p} .
\end{aligned}
$$

The resulting analytical expression allows us to determine the traction resistance of the broach-plow depending on its design parameters and the physical and mechanical properties of the soil.

Calculations using this formula for $b_{n}=0,5 \mathrm{M} ; b_{n}=0,032 \mathrm{м} ; \sigma=2 \cdot 10^{6} \Pi \mathrm{a}[1] ; \delta=0,004 \mathrm{M}$; $f=0,5$ [3]; $f_{l}=0,732$ [3]; $p=1,92 \cdot 10^{4}$ Па [1]; $p=1,64 \cdot 10^{4}$ Па [1]; $p_{1}=1,64 \cdot 10^{3}$ Па [3]; $t_{n}=0,015$ м; $\beta_{n}=25^{0} ; \beta_{n n}=25^{0} ; t_{n n}=0,006 \mathrm{~m} ; k=8 \cdot 10^{4}$ show that the traction resistance of the broachplow is determined by the installation angle of the plate to the bottom of the furrow $\alpha_{c}$, the plate length $l_{c \mathrm{~m}}$ and the width of the broach-plow wing $b_{k p}$, as well as the physical and mechanical properties of the soil.

With an increase in the angle of inclination of the plate's blade from 35 to 850 (Fig. 3a), the traction resistance of the broach-plow increases slightly by about 3.3\%. Поэтому значение угла $\alpha_{c}$ выбирается из условия резания почвы со скольжением, т.е. $\alpha_{c}<(\pi / 2-\varphi)$. Исходя из этого угол $\alpha_{\mathrm{c}}$ должен быть в пределах $50-60^{\circ}$.

From Fig. 3, b and Fig. 3c, it is clear that the traction resistance of the broach-plow as a function of the plate length and the width of the wing varies in a straight line.

A rational value of the broach-plow's width of the wing must be chosen taking into account the provision of incomplete turnover of the layer. It has been established that steady incomplete turnover of the layer is carried out with a broach-plow's wing width of 20-25 $\mathrm{cm}$.

The maximum length of the stabilizing plate is determined by the formula (3). By $b_{n}=50$ $\mathrm{cm} ; \gamma=45^{\circ}$ and $s=3 \mathrm{~cm}$, maximum plate length is $29,24 \mathrm{~cm}$.
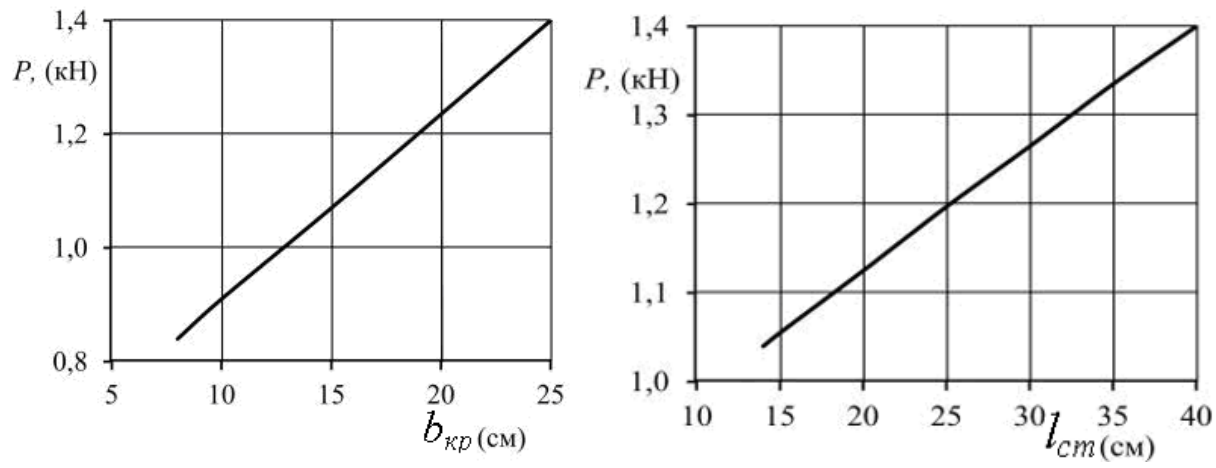

Fig. 3. The dependence of traction resistance of the broach-plow from the width of the wing $b_{\kappa p}$ and plate length $l_{c m}$ of the broach-plow

\section{Conclusions}

1. With a longitudinal distance between the hulls of $0.5 \mathrm{~m}$, a required qualitative incomplete turnover of the layers with the lowest energy costs is provided with the following broach-plow's parameters of the odd hulls: the length of the broach-plow is $75 \mathrm{~cm}$, the width of the broachplow is $25 \mathrm{~cm}$, the height of the stabilizing plate is $15 \mathrm{~cm}$, and the minimum distance $25 \mathrm{~cm}$.

2. An installation angle of the plate to the furrow bottom, the length of the plate and the 
width of the wing holders, as well as the physical and mechanical properties of the soil have a significant impact on the traction resistance of the hedge.

\section{References}

1. A.T. Vagin, Mechanization of soil protection from water erosion in the Nonchernozem strip. - Leningrad: Kolos, pp. 272 (1977)

2. K.V. Alexandryan, A.A. Gasparyan, K.G.. Karakhanyan, Machines for the development of mountain slopes and combat water erosion of soil. M., Agropromizdat, pp. 191 (1985).

3. M.M. Murotov, P.I. Бaymetov, N.S. Bibutov, Mechanical and technological bases and parameters of tools for soil decompression, Uz Academy of Sciences, pp.101 (1988)

4. O.R. Kenjaev, Justification of the technological parameters of the combined plow for strip-cross soil decomposition in the cotton growing area. Autoref. Diss. cand. tech. sci. $M$, pp. 18 (1990)

5. А.Т. Vagin, Interaction of the wedge with the soil // Works ЦНИИМ и ЭСХ Nechernozem zones, Agricultural mechanics issues, Minsk, pp. 36-65 (1965)

6. M.S. Makarova, Parameters of the sloping fields processing with lame plows, Autoref. diss. cand.tech.sci., Zernograd, pp.21 ( 2000)

7. F.M. Маматоv, Mechanical and technological substantiation of technical means for the main tillage in cotton sowing zones, Diss. D. tech. schi., Moscow, pp. 33 (1992)

8. I.T. Ergashev, Mechanical - technological basis of technology and technical means for smooth furrow ploughing, Diss. D. mech. sci., Yangiyul, pp. 41 (2003)

9. M.S. Maksimenko, Justification of the location and parameters of the stand of the front plow broach-plow, Sb.scientific works МИИСП, (1989)

10. V.V. Sharov, Justification of the main parameters of the rotary plow for smooth ploughing, Diss. cand. tech. sci., pp. 227 (1986)

11. M.S. Maкsimenko, Justification of the location and parameters of the front broachplow plow stand, Sb.scientific works МИИСП, (1989)

12. Patent RUz FAP 00863. Plow, F.M. Mamatov, B.S. Mirzaev et al., Official Bulletin, 1 (2014)

13. B.S. Mirzaev, Improvement of technologies and technical means for anti-erosion tillage in the conditions of Uzbekistan, Diss. D. mech. sci., Tashkent, pp. 200 (2015) 